\title{
Further evidence for a time-independent shift of the focus of attention
}

\author{
HO-WAN KWAK, DALE DAGENBACH, and HOWARD EGETH \\ Johns Hopkins University, Baltimore, Maryland
}

\begin{abstract}
The separation between stimuli was manipulated in a same-different matching task. In Experiment 1, stimuli were upright Ts and/or Ls, whereas in Experiment 2, they were rotated Ts and/or Ls. In both experiments, mean reaction time (RT) for the same-different judgment did not increase as a function of interletter separation, suggesting either that the time needed to relocate attention was independent of distance, or that the stimuli were processed in parallel. These alternatives were tested in a third experiment, with a diagnostic for parallel processing proposed by Egeth and Dagenbach (1991). The diagnostic indicated that the rotated Ts and Ls in Experiment 2 were processed serially. If serial processing implies the utilization of attention, then the results of Experiment 2 suggest that relocation of attention is time-invariant with respect to distance.
\end{abstract}

It is widely accepted that attention can be shifted from one location in the visual field to another without any shifting of eye position (Helmholtz, 1850/1925; Jonides, 1981; Posner, 1980). However, the nature of the attention shift is less clear. Does attention move in an analog, continuous fashion, or is the shift of attention from one location to another accomplished without movement per se?

The answer to this question is unclear, despite the fact that many researchers have tried to shed light on the mechanisms and structures that subserve the relocation of attention (Downing \& Pinker, 1985; Eriksen \& St. James, 1986; Eriksen \& Webb, 1989; Kröse \& Julesz, 1989; LaBerge, 1983; Murphy \& Eriksen, 1987; Posner, 1980; Remington \& Pierce, 1984; Sagi \& Julesz, 1985; Shulman, Remington, \& McLean, 1979; Tsal, 1983). From the results of these studies, three broad accounts of the shifting of attention have emerged. (1) Attention has been likened to a spotlight that moves at an essentially constant velocity and therefore takes more time to move a greater distance (Posner, 1980; Shulman et al., 1979; Tsal, 1983). Some forms of this account might also be seen as predicting that information appearing in the path of the attention shift between attended locations should be processed. (2) Attention has been characterized as a gradient of processing resources, with resources diminishing as distance from the focus increases. On this account, there is no need to assume a moving spotlight of attention. Distance effects

\footnotetext{
This research was supported in part by Grant 87-0180 from the Air Force Office of Scientific Research and Grant BNS-8919554 from the National Science Foundation, both to Howard Egeth, and by NIMH Postdoctoral Training Grant 5T32M 18275-03 to Johns Hopkins University. The authors would like to thank Bill Bacon, Bruce Hamill, Doug Johnson, Jung-Oh Kim, Fred Merkel, Toby Mordkoff, and Steve Yantis for helpful discussions and comments on this research, and Dina Kargon for helping to test the subjects. Address correspondence concerning this article to Howard Egeth, Department of Psychology, Ames Hall, Johns Hopkins University, Baltimore, MD 21218.
}

are due to the gradient of attentional resources, which is assumed to be distributed over the visual field (LaBerge, 1983; LaBerge \& Brown, 1989). When a target is presented close to the focus of attention, the response will be relatively fast, because of the high activity level at that point. When a target is presented far from the focus, the response will be relatively slow, because of the reduced activity level at that location. (3) Attention has been described as shifting from one location to another in a discrete, abrupt manner, so that it does not take longer time to move longer distances (Eriksen \& Murphy, 1987; Eriksen \& Webb, 1989; Murphy \& Eriksen, 1987; Remington \& Pierce, 1984; Sagi \& Julesz, 1985). This kind of shift has been described as noninertial by Sagi and Julesz (1985).

To distinguish among these accounts has proven difficult, partly because of methodological problems in the experiments on which the accounts are based and partly because of the complexity of the tasks that some researchers have employed (for critiques, see Eriksen \& Murphy, 1987; Yantis, 1988). In many situations, attention-like processes seem to move through space in an analog fashion. Operations on mental images have been characterized in this way (e.g., Kosslyn, 1973; Shepard \& Metzler, 1971), and also for certain topological questions to be answered, analog processing seems to be required. For example, Ullman (1984) and Pringle and Egeth (1988) have argued that perceivers deploy a curve-tracing routine to determine whether two designated points fall on a single line; the perceiver appears to trace visually along the line in order to make the judgment, even under conditions in which intuition suggests that this is not an efficient way to answer the question.

Although such findings would seem to make the notion that attention shifts abruptly from one location to another somewhat less plausible, a recent set of experiments by Sagi and Julesz (1985) seems to provide good evidence for just such abrupt relocation. In their experiments, sub- 
jects were required to decide whether two stimuli presented simultaneously at varying separations for a brief period of time and followed by a pattern mask were the same or different. Sagi and Julesz's data indicated that subjects' accuracy at a given display-mask stimulus onset asynchrony (SOA) was independent of distance, which they interpreted as evidence for "fast, noninertial shifts (pp. 141)" of attention. That is, attention may be directed from location to location, but not in an analog fashion, because if such were the case, more time would be required for attention to traverse a greater distance.

Sagi and Julesz's (1985) finding cannot easily be dismissed, for their experiments contained several methodological improvements over previous research. First, the stimuli were displayed on the perimeter of an imaginary circle centered in the visual field, to ensure that acuity was comparable for all stimuli. Second, the stimuli required a relatively subtle discrimination. In some of the previous studies, subjects simply had to detect a spot of light or discriminate an $X$ from an $O$. It may be possible for subjects to distribute attention broadly in such situations, in which case it may not be necessary to move attention to perform the task, or it might be that subjects are able to make the required judgment preattentively. In the Sagi and Julesz study, the subjects were required to determine whether the two letters ( $\mathrm{T}$ and $\mathrm{L}$ ) presented on each trial were the same or not. The Ts and Ls were randomly rotated; under such circumstances, it seems likely that serial processing is required (see, e.g., Bergen \& Julesz, 1983; Wolfe, Cave, \& Franzel, 1989).

Because their claim that the movement of attention was inertialess would not apply if processing were parallel, Sagi and Julesz (1985) included a number of tests to try to get at this question. One test involved comparing twostimulus discrimination accuracy with single-stimulus identification accuracy as a function of display-mask SOA. A serial processing model predicts that it should take more time to process two targets rather than one, and therefore performance in the two-stimulus discrimination task should be poorer than performance in the single-stimulus identification task, given the same exposure durations. The results were consistent with this prediction. On the whole, the psychometric function indicated that in order for subjects to attain comparable accuracy with the one- and twostimulus displays, the display-mask SOA had to be increased by approximately $\mathbf{4 0} \mathrm{msec}$ in the latter condition. In this connection, it was pointed out that the $40-\mathrm{msec}$ shift in the psychometric function gives an estimate of per element processing time that is at least roughly consistent with earlier estimates based on different methods (see, e.g., Bergen \& Julesz, 1983; Treisman \& Gelade, 1980).

However, this evidence for serial processing seems problematic for two reasons. First, it compares performance on two very different tasks, identification and discrimination. Second, this analysis relies on what is in essence a load manipulation, in that it involves a comparison between performance with one target (identification) and performance with two targets (discrimination). In one ex- periment, there were actually one or two targets present. In another experiment, display size was fixed at two, but one of the stimuli was in a fixed position. During the identification task, the fixed stimulus could be ignored, whereas during the discrimination task, it could not; thus, the effective display sizes differed for the two tasks. For reasons spelled out by Townsend (e.g., 1971, 1990), parallel and serial models cannot be discriminated simply through the examination of performance under varying load.

Sagi and Julesz (1985) provided further evidence for serial processing of targets by examining the consequences of successively, rather than simultaneously, presenting the two stimuli that were to be discriminated. The rationale was that such sequential presentation would disrupt parallel processing, but not serial processing. Sagi and Julesz found that one target could be delayed by $30-40 \mathrm{msec}$ relative to the other without affecting performance. They interpreted this as further evidence that the two stimuli are processed serially. Yet although this result is indeed consistent with serial processing, it does not seem compelling. It is possible that the use of a successive presentation paradigm may have induced the subjects to process serially stimuli that they would have processed in parallel had the stimuli been presented simultaneously.

Another problematic factor in Sagi and Julesz's (1985) experiments is that the introduction of a postmask may have complicated the processing of the display (Eriksen, 1980). Specifically, it is possible that the same masking display may affect the various levels of interletter distance and display types differently, so that a genuine effect of attention movement may have been canceled out. The use of a postmask may also produce a data-limited situation, in which the effects of attention shifts may be difficult to obtain (Norman \& Bobrow, 1975).

Finally, it is in any case worth keeping in mind that Sagi and Julesz (1985) report the data of just 2 subjects, and the curves for those subjects are not smooth enough to permit drawing firm conclusions.

In summary, Sagi and Julesz's (1985) data concerning the relation of discrimination accuracy to distance between the stimuli appear to be quite strong, except for the possible complications introduced by the postmasking procedure. However, their supplemental data showing that processing was serial are suggestive but not entirely convincing.

Our purpose in the present experiments was twofold. First, we wished to determine whether Sagi and Julesz's (1985) finding concerning the relation of discrimination performance to separation between stimuli would generalize to experiments wherein reaction time (RT), rather than accuracy, was the dependent measure. This would allow us to avoid possible artifacts arising from the use of masking procedures. In Experiment 1, the stimuli were upright Ts and Ls, whereas in Experiment 2, they were rotated Ts and Ls. This allowed for comparisons of the effect of distance, with stimuli that were more or less discriminable from one another. Second, we wished to use a converging operation to explore further the issue of whether or not processing under conditions yielding no 
distance effect might be due to parallel encoding. This was done in Experiment 3.

\section{EXPERIMENT 1}

\section{Method}

Subjects. Six undergraduate students from Johns Hopkins University participated in return for course credit. All had normal or corrected-to-normal vision.

Apparatus. An IBM PC/AT personal computer with an NEC Multisync monitor was used to present stimulus displays and to collect subjects' responses. This monitor does not give the subjective impression of leaving any visible screen persistence following stimulus offset, even when white stimuli are used on a black background.

Stimuli. The two letters in the target display were placed at systematically varied distances from each other on the perimeter of an imaginary circle whose diameter was about $9^{\circ}$ of visual angle at a viewing distance of $50 \mathrm{~cm}$. Each letter in the display subtended $.8^{\circ} \times .8^{\circ}$ of visual angle. The distance between the letters was varied to produce five levels of interletter distance, with resulting centerto-center separations of $2.3^{\circ}, 4.5^{\circ}, 6.5^{\circ}, 8.0^{\circ}$, and $9.0^{\circ}$ of visual angle. Apart from the constraint concerning separation, the letters were placed randomly on the circle. In this experiment, they were always in an upright orientation, and they appeared white against a black background.

Procedure. The subjects were tested individually in a dimly lit room. Each trial began with the presentation of a centered " + ", sign for $500 \mathrm{msec}$, which served as a fixation point. The subjects were instructed not to move their eyes from this point until they had made a response. After a 300-msec blank field, a target display containing two letters appeared for $150 \mathrm{msec}$. This short exposure duration was used in order to prevent eye movements.

On each trial, the subjects were required to indicate whether the two letters in the target display were the same or not by pressing one of the keyboard buttons, with the assignment of keys to same and different responses counterbalanced between subjects. The display could contain two Ts, two Ls, or a $T$ and an $L$, with an equal overall probability of same and different trials. The instructions stressed that the subjects should respond as quickly as possible while maintaining over $90 \%$ accuracy. If a subject made an error, an " $X$ " appeared on the center of the display for $500 \mathrm{msec}$, followed by the next trial after a 1.5 -sec intertrial interval.

Three blocks, each consisting of 10 practice and 160 experimental trials, were presented to each subject. The order of presentation of trials in each block was randomized, apart from the constraint that no more than four consecutive trials could require an identical response. The subjects were allowed to rest several minutes after finishing each block.

Design. A two-way repeated measures design was used with 2 levels of response type (same vs. different) $\times 5$ levels of interletter distance. For each condition of response type and distance, there were 16 replications.

\section{Results and Discussion}

Mean RTs and error rates for each condition in Experiment 1 are presented in Figure 1. Same responses tended to be faster than different responses, but there seemed to be no effect of interletter distance. A 2 (response type) $\times 5$ (interletter distance) analysis of variance (ANOVA) of the mean correct RTs confirmed this pattern. There was a significant main effect of response type $[F(1,5)=$ $7.88, p<.05]$, indicating that same responses were faster than different responses. The main effect of interletter distance was not significant $[F(4,20)<1]$, but there was

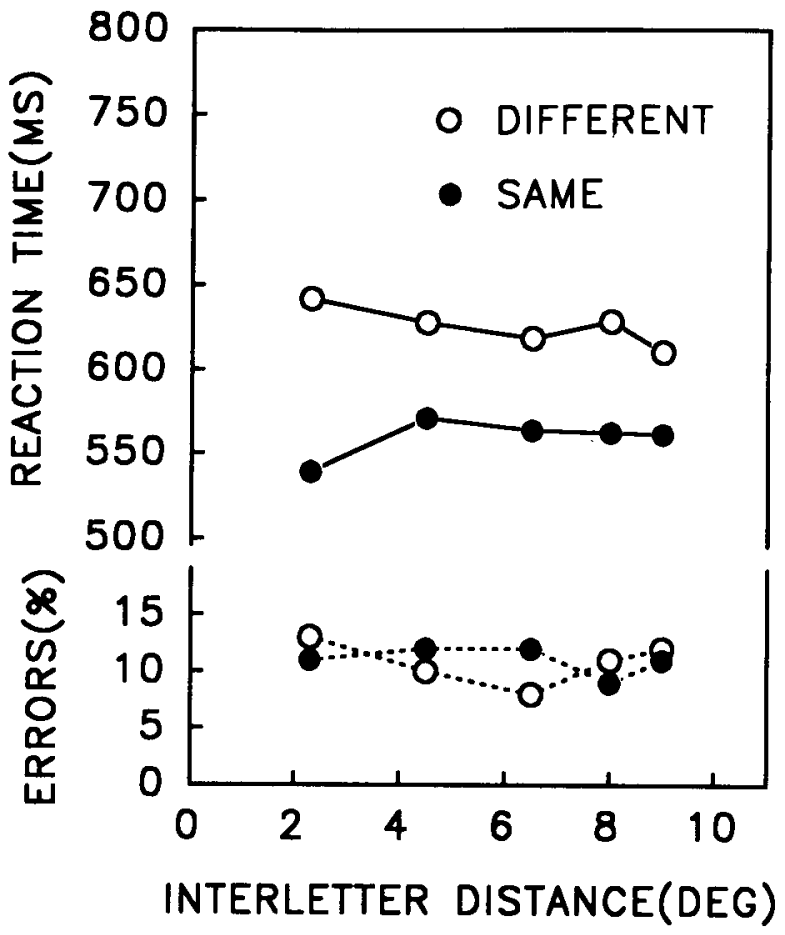

Figure 1. Mean reaction time and error rate as a function of response type and interletter distance in Experiment 1. Interletter distance is measured in degrees of visual angle.

a significant interaction between response type and interletter distance $[F(4,20)=3.62, p<.05]$.

To gain further insight into the significant interaction, simple main effects were calculated for the same and different conditions. While the simple main effect of distance in the same condition did not reach significance $[F(4,20)=$ $1.2]$, the simple effect of distance in the different condition did $[F(4,20)=5.13, p<.01]$. The significant simple main effect in the different condition was due to mean RT decreasing as distance increased. Thus the effect of distance, when there was one, was in direct opposition to the prediction of an analog, moving-spotlight model of attention.

Mean error rates in Experiment 1 were fairly high, averaging about $11 \%$, presumably due to the short duration of the stimulus display. However, an ANOVA of the accuracy data yielded no significant main effect of interletter distance or response type and no interaction between these factors.

One difference between the present results and those of Sagi and Julesz (1985) is that there was no indication of a performance decrement in the nearest distance condition in the present experiment. Sagi and Julesz attributed their finding of a performance decrement with close stimuli to lateral masking. Although there are several possible explanations of the difference in results, perhaps the simplest is that their closest stimuli were closer than ours, approximately $1.1^{\circ}$ versus $2.3^{\circ}$ for roughly comparable display diameters $\left(8^{\circ}\right.$ vs. $\left.9^{\circ}\right)$. 
Overall, the present results replicate Sagi and Julesz's (1985) failure to find a distance effect, suggesting that if serial attention is required in the present task, it does not require more time to move across a greater distance between two locations. The present effect was obtained without the possible artifacts introduced by masking procedures in their experiment. However, it is possible, perhaps even likely (see, e.g., Egeth \& Dagenbach, 1991), that the lack of distance effect reflects parallel processing rather than a time-independent shift of attention.

\section{EXPERIMENT 2}

In Experiment 2, Sagi and Julesz's (1985) study was replicated more directly with rotated Ts and Ls. Many investigators have claimed that such rotated characters are processed serially (see, e.g., Bergen \& Julesz, 1983; Egeth \& Dagenbach, 1991; Wolfe, Cave, \& Franzel, 1989).

\section{Method}

Subjects. Eight subjects from Johns Hopkins University participated in Experiment 2. Each subject received $\$ 5.00$ in return for participating.

Stimuli and Procedure. The stimuli and procedure were the same as those in Experiment 1, with the following exceptions: The Ts and $L s$ appeared in four different rotations: $0^{\circ}, 90^{\circ}, 180^{\circ}$, and $270^{\circ}$. Therefore, for each combination of response type and distance, there were 16 possible combinations of the two letters. Interletter distances were $1.8^{\circ}, 3.6^{\circ}, 5.4^{\circ}, 7.2^{\circ}$, and $9.0^{\circ}$ of visual angle. Finally, to increase the baseline accuracy level, the target displays were presented for $200 \mathrm{msec}$.

A total of 640 trials were randomized and divided into four subblocks of 160 trials. Before each sub-block, 10 practice trials were run. The subjects were instructed to respond on the basis of letter identity, rather than letter orientation. The subjects were allowed to rest several minutes after finishing each sub-block.

\section{Results and Discussion}

Figure 2 shows mean RTs and error rates as a function of response type and interletter distance in Experiment 2. A 2 (response type) $\times 5$ (interletter distance) ANOVA of mean correct response times for each subject was performed. As in Experiment 1, same responses were faster than different responses $[F(1,7)=13.59$, $p<.01]$. This time, interletter distance also produced a significant main effect $[F(4,28)=3.98, p<.05]$. Although the interaction between response type and distance was only marginally significant $[F(4,28)=2.47$, $.05<p<.1$, inspection of Figure 2 indicates that the significant effect of distance is due to mean RT decreasing as interletter distance increased, mainly in the different condition. Analyses of simple main effects revealed that although the effect of distance in the different condition was significant $[F(4,28)=3.57, p<.05]$, the effect in the same condition was not $[F(4,28)=1.83]$. Thus, the distance effect obtained in the different condition contradicts the claims made by a moving-spotlight model. An ANOVA of the accuracy data in Experiment 2 yielded no significant main effect or interaction between response type and interletter distance.

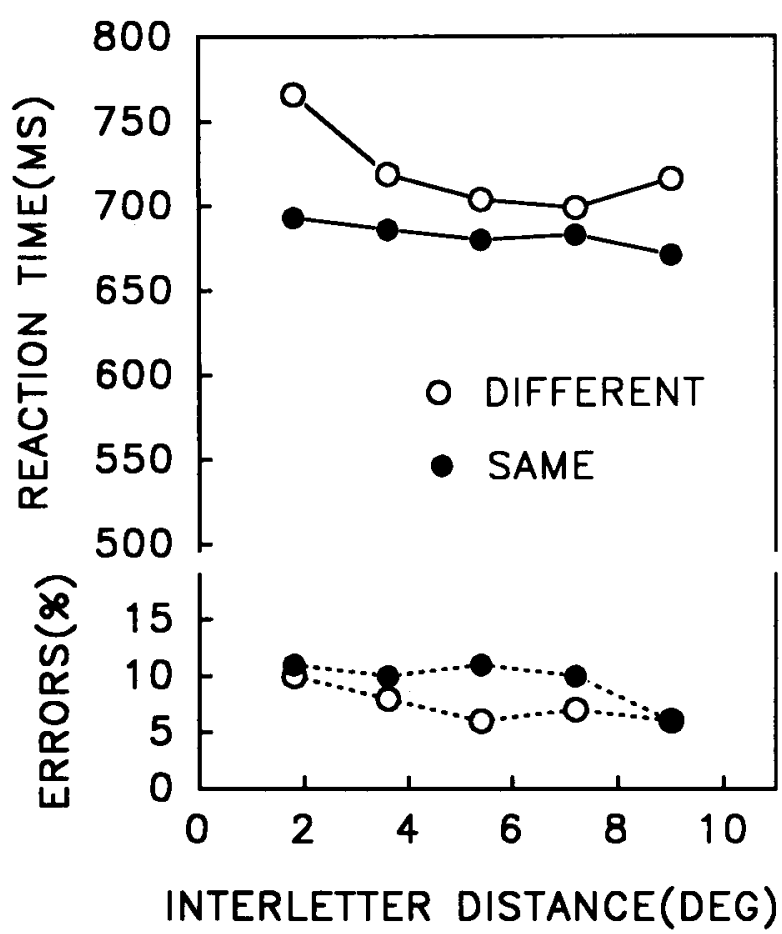

Figure 2. Mean reaction time and error rate as a function of response type and interletter distance (in degrees of visual angle) in Experiment 2.

The results of Experiment 2 were again generally consistent with the findings of Sagi and Julesz (1985). The slowdown in performance detected in the nearest condition may have been a consequence of a lateral masking effect between the adjacent letters (Sagi \& Julesz, 1985). Although there was no such effect in Experiment 1, letters in the close condition in this experiment were, in fact, slightly closer than in the corresponding condition of Experiment $1\left(1.8^{\circ}\right.$ rather than $\left.2.3^{\circ}\right)$. This account, however, would not address the question of why the effect in the present experiment seemed to show up only in different trials. Regardless of the basis of the increment in response time for the closest distance condition relative to the other distance conditions on the different trials, the general pattern clearly indicated no systematic increase of response time as interletter distance increased.

\section{EXPERIMENT 3}

Although the results of Experiments 1 and 2 were consistent with those of Sagi and Julesz (1985) and replicated the findings that they obtained with a response time measure, they did not rule out the possibility that the lack of distance effects might be due to parallel processing of the stimuli. To be sure, in other studies in which rotated Ts and Ls have been used, it has been claimed that these were processed serially, but those experiments involved a visual search paradigm, rather than the same-different task employed in the present experiments. Therefore, it remained 
possible that the lack of a distance effect was a consequence of parallel processing.

To directly address this issue, we employed a diagnostic based on testing for subadditive effects of a withintrial visual quality manipulation (Egeth \& Dagenbach, 1991). This diagnostic applies to situations in which processing of stimuli must be exhaustive. In a same-different matching task, both stimuli must of necessity be examined to achieve a correct response, and thus the diagnostic may be applied to the data from both same and different trials.

The diagnostic works as follows. Consider the three possible kinds of displays that can occur with two stimuli present and visual quality varied orthogonally: Both stimuli may be of high quality (e.g., high contrast); both may be of low quality (e.g., low contrast); or one may be of high quality and the other may be of low quality. Further, assume that the processing time of the low-quality stimulus is longer than that of the high-quality stimulus. To be concrete, let us assume that it takes $20 \mathrm{msec}$ more to process a low-quality stimulus than it takes to process a high-quality stimulus. If processing is serial, then the time to process two low-quality stimuli will be $40 \mathrm{msec}$ longer than the time to process two high-quality stimuli. The time required to process one high- and one lowquality stimulus should be just $20 \mathrm{msec}$ longer than the time required to process two high-quality stimuli.

In contrast, a parallel model predicts a different pattern of results. On the common analogy of the horse race, processing must wait for the slower horse to finish the race (in a two-horse race). With two high-quality stimuli, we have two fast horses racing. However, with two lowquality stimuli or with one low-quality and one highquality stimulus, we have a situation in which there is at least one slow horse. Processing will be slow in both cases. In other words, the low-quality stimulus is the limiting factor if processing is parallel and exhaustive. Processing may not be equally slow in the high-low and low-low conditions, because of statistical considerations concerned with the degree of overlap between distributions of processing times (Egeth and Dagenbach, 1991); but what is the case is that the difference in the processing time between the high-low quality display and low-low quality display should not be as large as the difference in processing time between the high-high and high-low displays. This is what is meant by subadditivity. ${ }^{1}$

Egeth and Dagenbach (1991) have pointed out that the diagnostic is asymmetric. The presence of subadditivity implies parallel processing, but its absence does not necessarily imply serial processing. No doubt the simplest interpretation of additive data is that processing is serial. However, a limited-capacity parallel system with processing of the targets on separate channels could generate an additive pattern of data if some additional assumptions were made concerning overlap between distributions of processing time. Thus, the diagnostic is not a perfect tool for distinguishing parallel and serial processing. ${ }^{2}$ However, it provides a potentially useful converging operation for assessing processing mode. It is particularly ap- propriate to the present investigation, because it permits examination of processing mode with just two stimuliwhich is, of course, precisely the number of stimuli involved in the discrimination task.

Using the logic described above in a visual search task, Egeth and Dagenbach (1991) examined several combinations of target and distractor stimuli. They found subadditive effects of visual quality on the response times, suggesting parallel processing, when the target and distractor items were Xs and Os and, as in the present Experiment 1, canonical Ts and Ls (the designation of the stimuli as target or distractor was counterbalanced between subjects). On the other hand, there was no subadditive effect in search with rotated Ts and Ls, suggesting that the processing of these stimuli may have been serial. The question to be answered in Experiment 3, then, was whether the processing of rotated Ts and Ls might also be serial in the same-different comparison task. If so, then Experiments 2 and 3 would show that shifts of attention are independent of the spatial extent of the shift.

\section{Method}

Subjects. Ten undergraduate and graduate students from Johns Hopkins University participated in return for $\$ 5.00$. None of them had participated in the previous experiments. One subject's data were deleted from the subsequent analyses because the subject misunderstood the instructions, resulting in mean response times of over 1 sec.

Procedure and Stimuli. The stimuli and procedures were the same as those in Experiment 2, with the exception of the following changes made in the display. The stimuli were drawn in black and dark gray against a white background, so that we could use the same procedures as Egeth and Dagenbach (1991) used, with the monitor's brightness increased and the contrast decreased to magnify the difference in discriminability between characters presented in the two colors. These black and gray stimuli represented high and low visual quality, respectively. In the high-quality condition, both of the letters were drawn in black. In the mixedquality condition, one of them was black and the other gray. In the low-quality condition, both of them were gray.

There were three levels of interletter distance, with the stimuli separated by $3^{\circ}, 6^{\circ}$, and $9^{\circ}$ of visual angle.

Finally, the duration of the target display was increased to $250 \mathrm{msec}$.

Design. A three-way repeated measures design was used: 2 (same-different) $\times 3$ (interletter distance) $\times 3$ (visual quality: high, mixed, low) $\times 32$ (16 combinations of orientation $\times 2$ replications of each). A total of 576 experimental trials were presented to each subject. After randomization of trials, they were divided into 6 subblocks, each of which began with 10 practice trials.

\section{Results and Discussion}

In Figure 3, mean RTs and error rates are shown for each combination of response type and visual quality in Experiment 3. An ANOVA of the mean correct RTs showed a significant effect of visual quality $[F(2,18)=$ $17.89, p<.001]$, reflecting an increase in response time as visual quality decreased.

The claim of the subadditivity diagnostic is that if processing is parallel, the difference in mean RT between responding in the low-quality condition relative to the mixed-quality condition should be less than the difference 


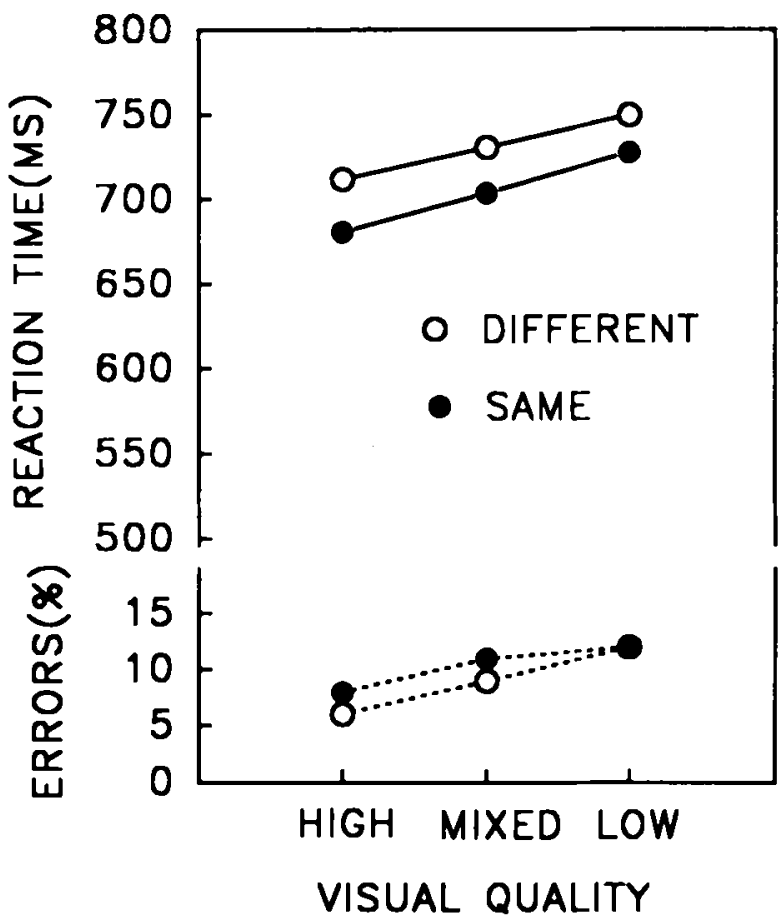

Figure 3. Mean reaction time and error rate as a function of response type and visual quality in Experiment 3.

in mean RT between the mixed- and high-quality conditions. Figure 3, in which mean reaction time is shown as a function of visual quality and response type, presents visual evidence indicating that this did not occur.

In order to test directly whether the visual quality effect was subadditive, difference scores were calculated for each subject. These scores were based on the difference between the RTs in the high- and mixed-quality conditions, and on the difference between the RTs in the mixed- and low-quality conditions. If the effect of visual quality were subadditive, as predicted by a parallel processing model, then the first difference would be greater than the second. An ANOVA of the difference scores revealed no significant difference between the two sets $[F(1,9)<1]$, suggesting no indication of subadditive effects of visual quality. Rather, the effects of visual quality in Experiment 3 appear to be additive.

Additivity was confirmed by a trend analysis of the effect of visual quality, which revealed a significant linear component $[F(1,18)=32.44, p<.001]$, explaining over $99 \%$ of the variance. A quadratic component did not reach significance $[F(1,18)<1]$. The additive effects of visual quality are consistent with the interpretation that the discrimination of rotated Ts and $L s$ indeed requires serial processing.

As in Experiment 2, we again failed to obtain distance effects in Experiment $3[F(1,9)<1]$. In Figure 4, mean RTs and error rates are shown as a function of interletter distance and response type in Experiment 3. Inspection of this figure shows that there is no sign that slower response times accompany increases in distance between letters.
The average error rate across subjects was $8 \%$. An ANOVA of the accuracy data yielded a significant main effect of visual quality $[F(2,18)=6.45, p<.01]$, reflecting poorer identification of low-quality stimuli. This pattern of results is consistent with the RT data, and it does not suggest the presence of a speed-accuracy tradeoff. No other main effect or interaction reached significance.

In conjunction with the additive effects of visual quality indicating serial processing of the stimuli, the flat function of the distance effect clearly indicates that it does not require more time to relocate attention over a longer distance. These two findings occurring together in the same experiment provide support for claims that attention shifts are time-invariant (Eriksen \& Webb, 1989; Remington \& Pierce, 1984), or fast and noninertial (Sagi \& Julesz, 1985). ${ }^{3}$

\section{GENERAL DISCUSSION}

In Experiments 1 and 2, there was no evidence of a distance effect for the same-different discrimination of either upright or rotated Ts and Ls. This replicated and extended the important empirical result of Sagi and Julesz (1985).

The central theoretical question underlying the present research is whether attention takes more time to move a greater distance. In combination, the results of Experiments 2 and 3 suggest that the answer is no. Experiment 3 established that to match rotated Ts and Ls requires serial processing. Experiments 2 and 3 established that that matching task does not take longer the farther apart the letters.

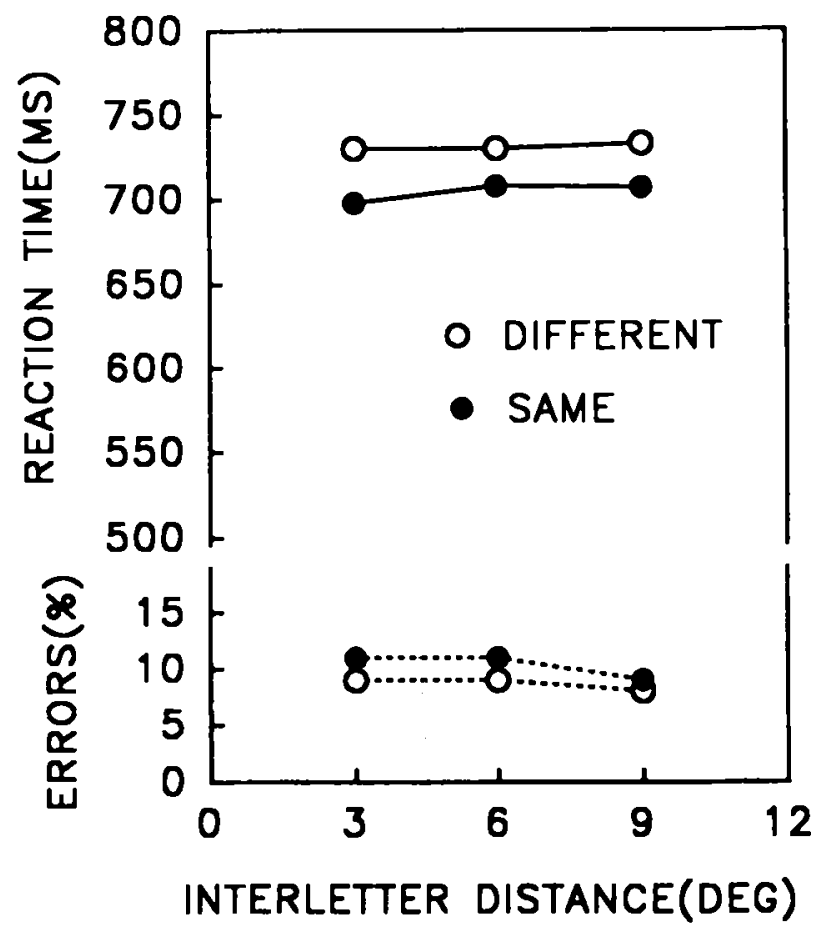

Figure 4. Mean reaction time and error rate as a function of response type and interletter distance (in degrees of visual angle) in Experiment 3. 
If serial processing had not been established in Experiment 3, the results of Experiments 2 and 3 could not have been taken to speak to the question at issue. This is because a lack of a distance effect alone cannot be definitive evidence regarding the nature of attention movements. Converging evidence is required in order for one to eliminate alternative hypotheses. This means that at least some of the previous studies addressing the movement of attention may not have been adequate for testing the nature of attention shifts. For example, in an experiment in which subjects were required to detect a dot or a spot of light, or to discriminate an $O$ from an $X$, the task could have been carried out by means of parallel processing. In this case, the data would not provide a convincing test regarding the nature of attention movements.

Are attention shifts inertialess? Different researchers use different terms for fast, abrupt shifts of attention. For example, Remington and Pierce (1984) refer to "timeinvariant shifts of attention," whereas Eriksen and Webb (1989) speak of "distance-independent indexing of locations." These two descriptions of attention shifts seem to have almost the same meaning, in that they both argue that attention does not require more time to shift longer distances. Indeed, these usages are consistent with the notion that there is no analog "movement" of attention at all (i.e., intermediate locations are not traversed), but that it is simply relocated or redeployed from one location to another. However, Sagi and Julesz (1985) introduced a slightly different term, referring to the phenomenon as "fast, noninertial shifts of attention." The latter phrase has some extra implications that may or may not be warranted, but these are certainly interesting to consider. By "'noninertial," we take Sagi and Julesz to mean that the speed or efficiency of an attention shift should also be independent of the previous direction of attention's movement-it should not be any more difficult to redirect the movement of attention in a new direction than to continue in the same direction.

Finally, we should point out an alternative interpretation of the lack of a distance effect. Attention seems not to move in an analog fashion. This does not necessarily mean that it is correct to conclude that attention moves across space in an abrupt manner. Instead, the tasks given to the subjects in the present research and in previous, related research may be represented internally in a nonspatial format. For example, the subject may possess the equivalent of "T detectors" and " $L$ detectors" with wide receptive fields. When just one of these detectors has a high activation level on a given trial, the subject can respond "same." When both of these detectors have intermediate levels of activation, the subject can respond "different." Separation between stimuli would not necessarily affect performance on this account. Of course, to repeat a point made earlier, there are tasks that yield distance effects (see, e.g., Kosslyn, 1973; Pringle \& Egeth, 1988). There are, no doubt, good reasons why tasks should differ in the extent to which they necessitate the use of a spatial representation. For example, in scanning tasks of the sort used by Kosslyn (1973), subjects were asked to form an image. Such an instruction might prompt the subjects to use a spatial representation in a task that could be solved with a nonspatial representation. It is not obvious how to test the ad hoc alternative account that the subjects used a nonspatial representation in the present experiments. It is raised here not so much as a serious alternative to attentional interpretations as it is to remind the reader of the theoretical complexity of the topics under discussion. We, along with previous investigators, have simply assumed the plausibility of a spatially organized internal representation for the tasks we have chosen to test. The mind may not be organized in that way at all.

\section{REFERENCES}

BAMBER, D. (1969). Reaction times and error rates for "same""different" judgments of multidimensional stimuli. Perception \& Psychophysics, 6, 169-174.

Bergen, J. R., Julesz, B. (1983). Parallel versus serial processing in rapid pattern discrimination. Nature, 303, 696-698.

Dagenbach, D., \& Egeth, H. E. (1990, November). Using converging operations to test for parallel versus serial processing. Poster presented at the 31st annual meeting of the Psychonomic Society, New Orleans.

Dixon, P., Just, M. A. (1978). Normalization of irrelevant dimensions in stimulus comparisons. Journal of Experimental Psychology: Human Perception \& Performance, 4, 36-46.

Downing, C. J., \& Pinker, S. (1985). The spatial structure of visual attention. In M. I. Posner \& O. S. M. Marin (Eds.), Attention and Performance $X I$ (pp. 171-187). Hillsdale, NJ: Erlbaum.

EgETH, H. E. (1966). Parallel versus serial processes in multidimensional stimulus discrimination. Perception \& Psychophysics, 1, 245-252.

EGETH, H. [E.], BLECKER, D. (1971). Differential effects of familiarity on judgments of sameness and difference. Perception \& Psychophysics, 9(4), 321-326.

Egeth, H. E., \&agenbach, D. (1991). Parallel versus serial processing in visual search: Further evidence from subadditive effects of a visual quality. Joumal of Experimental Psychology: Human Perception \& Performance, 17, 550-559.

ERIKSEN, C. W. (1980). The use of a visual mask may seriously confound your experiment. Perception \& Psychophysics, 28, 89-92.

ERIKSEN, C. W., \& MURPHY, T. D. (1987). Movement of attentional focus across the visual field: A critical look at the evidence. Perception \& Psychophysics, 42, 299-305.

ErJKsen, C. W., ST. JAMES, J. D. (1986). Visual attention within and around the field of focal attention: A zoom lens model. Perception \& Psychophysics, 40, 225-240.

ERIKSEN, C. W., \& WeBb, J. M. (1989). Shifting of attentional focus within and about a visual display. Perception \& Psychophysics, 45, 175-183.

Helmholtz, H. von. (1925). Physiological optics (Vol. 3, P. C. Southan, Ed. \& Trans.). Washington, DC: Optical Society of America. (Original work published 1850)

JONIDES, J. (1981). Voluntary vs. automatic control over the mind's eye's movement. In J. B. Long \& A. D. Baddeley (Eds.), Attention and Performance $I X$ (pp. 187-203). Hillsdale, NJ: Erlbaum.

KossLyN, S. M. (1973). Scanning visual images: Some structural implications. Perception \& Psychophysics, 14, 90-94.

KRöse, B.J.A., \& Julesz, B. (1989). The control and speed of shift of attention. Vision Research, 29, 1607-1619.

LABERGE, D. (1983). Spatial extent of attention to letters and words. Joumal of Experimental Psychology: Human Perception \& Performance, 9, 371-379.

LABERGE, D., BRown, V. (1989). Theory of attentional operations in shape identification. Psychological Review, 96, 101-124. 
Murphy, T. D., ERiksen, C. W. (1987). Temporal changes in the distribution of attention in the visual field in response to precues. Perception \& Psychophysics, 42, 576-586.

Norman, D. A., Bobrow, D. (1975). On data-limited and resourcelimited processes. Cognitive Psychology, 7, 44-64.

POSNER, M. (1980). Orienting of attention. Quarterly Journal of Experimental Psychology, 32, 3-25.

Pringle, R., \& Egeth, H. E. (1988). Mental curve tracing with elementary stimuli. Journal of Experimental Psychology: Human Perception \& Performance, 14, 716-728.

Remington, R. [W.], \& Prerce, L. (1984). Moving attention: Evidence for time-invariant shifts of visual selective attention. Perception \& Psychophysics, 35, 393-399.

SAGI, D., JULESZ, B. (1985). Fast noninertial shifts of attention. Spatial Vision, 2, 141-149.

SANTEE, J. L., \& EGETH, H. E. (1980). Selective attention in the speeded classification and comparison of multidimensional stimuli. Perception \& Psychophysics, 28, 191-204.

ShePARD, R. N., Me MtzLer, J. (1971). Mental rotation of threedimensional objects. Science, 171, 701-703.

Shulman, G. L., Remington, R., \& McLean, J. P. (1979). Moving attention through visual space. Journal of Experimental Psychology: Human Perception \& Performance, 5, 522-526.

Townsend, J. T. (1971). A note on the identifiability of parallel and serial processes. Perception \& Psychophysics, 10, 161-163.

TOWNSEND, J. T. (1990). It was twenty years ago today: Increasing reaction times or errors still do not a serial processor make (Tech. Rep. No. 89-1). West Lafayette, IN: Purdue University, Purdue Mathematical Psychology Program.

Treisman, A. M., Gelade, G. (1980). A feature integration theory of attention. Cognitive Psychology, 12, 97-136.

TSAL, Y. (1983). Movements of attention across the visual field. Journal of Experimental Psychology: Human Perception \& Performance, 9, 523-530.

Ullman, S. (1984). Visual routines. Cognition, 18, 97-159.

Wolfe, J. M., Cave, K. R., \& Franzel, S. L. (1989). Guided search: An alternative to the feature integration model for visual search. Journal of Experimental Psychology: Human Perception \& Performance, $15,419-433$

Yantis, S. (1988). On analog movements of visual attention. Perception \& Psychophysics, 43, 203-206.

\section{NOTES}

1. There are other tests for subadditivity. Egeth \& Dagenbach (1991) presented two stimuli in fixed locations in a search task. They performed a $2 \times 2$ ANOVA in which the quality of the stimulus at one location was one factor and the quality of the stimulus at the other location was the other factor. Unfortunately, this very straightforward test cannot be readily applied in the present experiment, because stimulus locations were not fixed.

2. One potential problem that deserves mention is that if low-quality stimuli require more capacity (as opposed to just more time) to process than high-quality stimuli do, then we may be no better off in meeting Townsend's $\{1971,1990)$ criticisms than previous investigators have been. It is not yet clear that low-quality stimuli do require more capacity. In a search task with rotated Ts and Ls as stimuli, Dagenbach and Egeth (1990) factorially manipulated display size and quality-the stimuli were all high, all low, or half high and half low in quality. These two factors did not interact, which suggests that load and quality may affect different processing stages and thus may not be simply substitutable, one for the other.

3. One remaining question is whether the independence of RT and separation in Experiment 1 is the reflection of parallel processing or of a time-independent shift of serial attention. We had implicitly assumed that processing was parallel in Experiment 1 on the basis of our finding of subadditivity in a search task using upright Ts and Ls (Egeth \& Dagenbach, 1991). When we actually tested this assumption in a pilot experiment by manipulating quality in a same-different task, we found clear evidence of subadditivity. However, further analysis showed that that outcome obtained for same trials but not for different trials. The reason for the discrepancy is at present unclear. It may be that same and different responses are fundamentally different (see, e.g.,Bamber, 1969; Egeth \& Blecker, 1971). Alternatively, the data may be the result of an artifact such as response competition due to irrelevant variation in quality (see, e.g., Dixon \& Just, 1978; Egeth, 1966; Santee \& Egeth, 1980). (Such variation might be more prominent with orderly displays consisting of upright Ts and Ls as opposed to displays consisting of rotated Ts and Ls.) This is all highly speculative; further research is necessary.

(Manuscript received August 8, 1990; revision accepted for publication December 17, 1990.) 